Journal of Molecular Structure, 72 (1981) 143-152

Elsevier Scientific Publishing Company, Amsterdam - Printed in The Netherlands

\title{
THE MICROWAVE SPECTRUM, STRUCTURE AND DIPOLE MOMENT OF 1,4-PENTADIYNE
}

ROBERT L. KUCZKOWSKI, FRANK J. LOVAS and R. D. SUENRAM

Molecular Spectroscopy Division, National Bureau of Standards, Washington, D.C. 20234 (U.S.A.)

ROBERT P. LATTIMER, KURT W. HILLIG II and ARTHUR J. ASHE III

Department of Chemistry, University of Michigan, Ann Arbor, MI 48109 (U.S.A.)

(Received 18 August 1980)

\begin{abstract}
The microwave spectra of 1,4-pentadiyne and 1,4-pentadiyne-1,5- $d_{2}$ are assigned and rotational and centrifugal distortion constants obtained. A unique structure could not be determined. However, analysis of the moments of inertia indicates that the bond distances in $\mathrm{C}_{5} \mathrm{H}_{4}$ are close to typical values found in other related compounds. An interaction involving the acetylene moieties is evidenced by the derived bond angles. The data are consistent with either the central CCC angle being close to the tetrahedral value with the acetylene groups pushed away from linearity by approximately $3-4^{\circ}$ or opening of the central CCC angle to about $113^{\circ}$ along with linear acetylene groups. A range of structures between these two is also possible. The dipole moment is determined to be $0.516(5) \mathrm{D}$.
\end{abstract}

\section{INTRODUCTION}

1,4-Pentadiyne with two acetylene moieties bonded to the same carbon atom is an interesting species for investigation by microwave (MW) spectroscopy. The photoelectron spectrum of this compound has revealed electronic interactions between the nominally degenerate $\pi$ orbitals sufficient to result in three distinct $\pi$ orbital ionization energies [1]. This raises the question of whether some structural perturbations may also occur similar to the angular deformations observed for other acetylene groups such as in propynal [2], 1,8-bis-(prop-1-inyl)naphthalene [3] (cf. Fig. 1) or in isoelectronic malononitrile [4] (cf. Fig. 2).

The MW spectrum of pentadiyne should also be of interest as a possible interstellar species. The discovery of molecules such as $\mathrm{HC}_{n} \mathrm{~N}(n=1,3 \ldots$ 9) in interstellar clouds has led to proposals that acetylene-based ion chemistry gives rise to these long chains [5]. Such a reaction chemistry could also lead to linear acetylenic species $\left(\mathrm{HC}_{n} \mathrm{H}\right)$ and the non-linear 1,4 -pentadiyne. Pure rotational transitions of the linear species cannot normally be detected although it has been suggested that diffuse interstellar bands at $\lambda>4000 \AA$ could be due to long carbon-chain molecules [6]. 

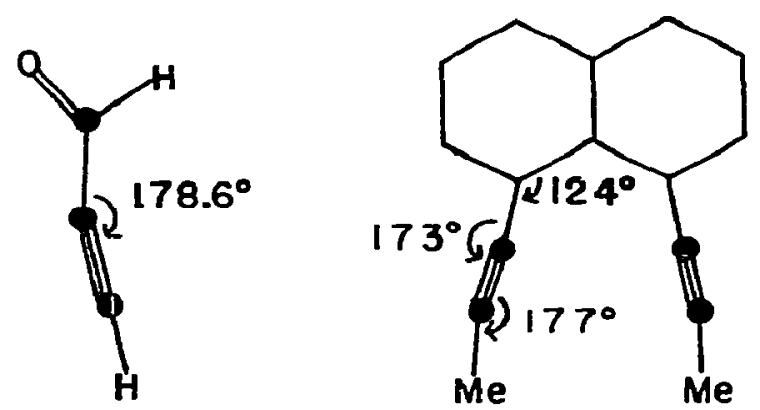

Fig. 1. Angular deformations in propynal [2] and 1,8-bis(prop-1-inyl)naphthalene [3].
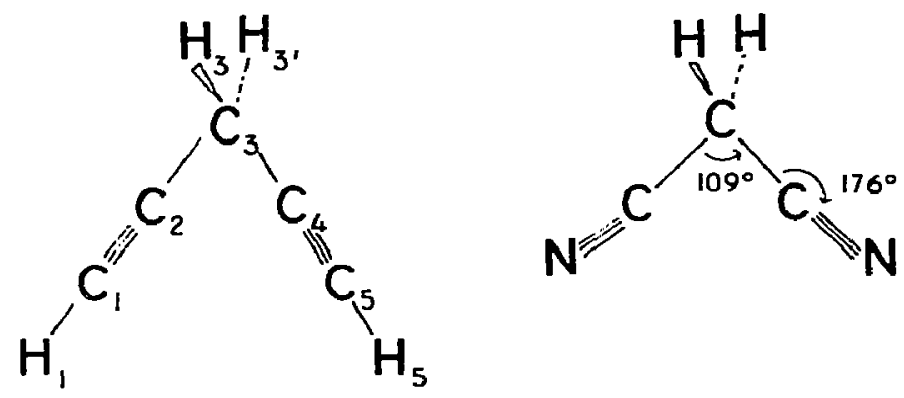

Fig. 2. Numbering scheme for 1,4-pentadiyne; angular deformation in malononitrile.

EXPERIMENTAL*

Materials

\section{1,4-Pentadiyne}

This was prepared by the cuprous chloride catalyzed coupling reaction of ethynyl magnesium bromide with propargyl bromide in tetrahydrofuran [7]. This reaction is inefficient and produces several products. The yields of product were low and variable $(1-20 \%)$ precluding the economical preparation of isotopic species. In the later stages of this study, 1,4-pentadiyne was supplied as a $10 \%$ solution in tetrahydrofuran-heptane from Farchan Division, Story Chemical Company, Willoughby, Ohio. Separation was achieved by gas-liquid phase chromatography (GLPC) on a Varian 90P chromatograph using a $2 \mathrm{~m} \times 1 \mathrm{~cm}$ column containing $20 \%$ Apiezon $\mathrm{L}$ on Chromosorb W. On elution at $70^{\circ} \mathrm{C}, 1.7 \times 10^{5} \mathrm{~Pa}$ helium pressure, 1,4-pentadiyne has a 2 min retention time.

\section{1,4-Pentadiyne-1,5- $\mathrm{d}_{2}$}

A solution containing $10 \mathrm{ml}$ of $10 \%$ 1,4-pentadiyne in tetrahydrofuranheptane was added to $100 \mathrm{ml}$ of dibutyl ether. After cooling to $-78^{\circ} \mathrm{C}$,

* Certain commercial instruments and materials are identified in this paper to specify adequately the experimental procedure. In no case does such identification imply recommendation or endorsement by the National Bureau of Standards, nor does it imply that the items identified are necessarily the best available for the purpose. 
$15 \mathrm{ml}$ of $1.24 \mathrm{~N}$ t-butyllithium in pentane was added dropwise. A large yellowish-white precipitate formed. After warming to $25^{\circ} \mathrm{C}, 75 \%$ of the solvent was removed in vacuo and $10 \mathrm{ml}$ of $\mathrm{D}_{2} \mathrm{O}$ was added. The organic layer was separated, dried over $\mathrm{MgSO}_{4}$ and distilled. 1,4-Pentadiyne-1,5- $d_{2}$ was separated by GLPC (see above). Enrichment was in excess of $90 \%$.

\section{Spectrometers}

The spectra were obtained using 33 and $80 \mathrm{KHz}$ Stark spectrometers with klystron and backward wave oscillator sources at the University of Michigan and the National Bureau of Standards (NBS). The measurements above 100 $\mathrm{GHz}$ were obtained on the NBS spectrometer using a phase locked OKI $120 \mathrm{~V} 10$ klystron under computer control [8]. The accuracy of the measurements was $\pm 0.2 \mathrm{MHz}$. However, many of the high frequency transitions were only partially modulated and their true line centers may be shifted by as much as $0.3 \mathrm{MHz}$ from the reported values. Spectra were normally recorded at temperatures of approximately $-25^{\circ} \mathrm{C}$ where the sample had sufficient vapor pressure.

\section{Spectra}

The spectrum was characteristic of a slightly asymmetric prolate top ( $\kappa=0.96)$ with $C_{2 v}$ symmetry and $\mu_{\mathrm{b}}$ transitions. This resulted in two prominent, low $K, R$ branch series with transitions separated by roughly $(B+C)$ and several $Q$ branch series with origins at rough multiples of $[A-1 / 2(B+C)](2 K+1)$. The initial assignment of several low $J$ transitions between 18-36 GHz was obtained from their resolved Stark effects. The centrifugal distortion parameters derived from these frequencies enabled a straightforward assignment of the millimeter-wave transitions. The $K^{\prime}=4$ $\leftarrow K^{\prime \prime}=3 Q$ branch series originating at $114.56 \mathrm{GHz}$ had transitions of opposite symmetry close enough to readily observe the 10:6 alternation of intensity expected for $C_{2 \mathrm{v}}$ symmetry. For example, the two $J=6$ transitions are illustrated in Fig. 3. The assigned transitions are listed in Table 1. The rotational constants and centrifugal distortion constants obtained from the Watson formulation [9] as programed by Kirchhoff [10] are listed in Table 3.

The doubly deuterated species, $\mathrm{CH}_{2}(\mathrm{C} \equiv \mathrm{CD})_{2}$, was synthesized (see above) and a number of low $J$ transitions were assigned. These transition frequencies are listed in Table 2. The derived rotational constants and centrifugal distortion constants are listed in Table 3 . The small number of transitions for this species (and the excited vibrational state described below) does not allow very well determined centrifugal distortion constants.

Considerable effort was expended to assign the ${ }^{13} \mathrm{C}$ species in natural abundance using the sensitive spectrometer at NBS. The high $J, R$ branch transitions in the region of $100-122 \mathrm{GHz}$ were intense enough for detection. However, it was difficult to obtain assignments which could be confidently 


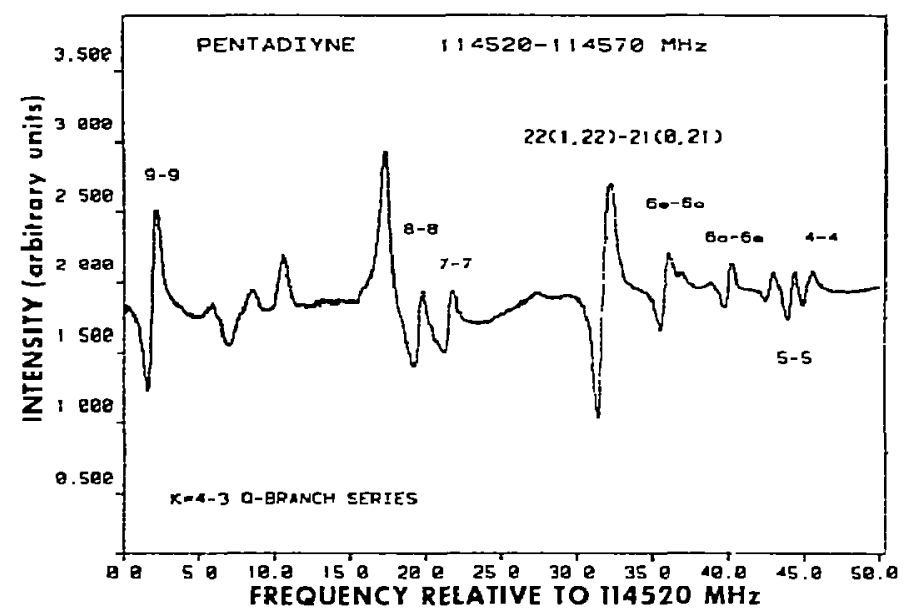

Fig. 3. Spectrum between $114.52-114.57 \mathrm{GHz}$. Stark field $=2500 \mathrm{~V} \mathrm{~cm}^{-1}$.

\section{TABLE 1}

Transitions assigned for the ground state of $\mathrm{C}_{5} \mathrm{H}_{4}$

\begin{tabular}{|c|c|c|c|c|c|}
\hline$J\left(K_{-}^{\prime}, K_{+}^{\prime}\right)-J^{\prime \prime}\left(K_{-}^{\prime \prime}, K_{+}^{\prime \prime}\right)$ & $\nu(\mathrm{MHz})$ & $\Delta \nu(\mathrm{MHz})^{\mathrm{a}}$ & $J\left(K_{-}^{\prime}, K_{+}^{\prime}\right)-J^{\prime \prime}\left(K_{-}^{\prime \prime}, K_{+}^{\prime \prime}\right)$ & $\nu(\mathrm{MHz})$ & $\Delta v(\mathrm{MH}:$ \\
\hline $2(1,1)-2(0,2)$ & 16899.14 & 0.00 & $14(2,13)-13(1,12)$ & 109584.52 & 0.04 \\
\hline $6(0,6)-5(1,5)$ & 18100.37 & 0.04 & $21(1,21)-20(0,20)$ & 109808.00 & 0.13 \\
\hline $4(1,3)-4(0,4)$ & 18143.73 & 0.03 & $18(4,14)-18(3,15)$ & 111968.50 & -0.02 \\
\hline $5(1,4)-5(0,5)$ & 19071.16 & 0.06 & $22(0,22)-21(1,21)$ & 111991.90 & -0.14 \\
\hline $6(1,5)-6(0,6)$ & 20225.36 & 0.05 & $14(4,10)-14(3,11)$ & 113790.93 & -0.03 \\
\hline $1(1,1)-0(0,0)$ & 21596.93 & -0.18 & $12(4,8)-12(3,9)$ & 114197.88 & 0.05 \\
\hline $7(1,6)-7(0,7)$ & 21627.28 & 0.06 & $6(3,3)-5(2,4)$ & 114255.51 & -0.26 \\
\hline $8(1,7)-8(0,8)$ & 23299.28 & 0.03 & $11(4,7)-11(3,8)$ & 114324.65 & 0.10 \\
\hline $7(0,7)-6(1,6)$ & 24244.96 & 0.02 & $16(4,13)-16(3,14)$ & 114353.96 & -0.06 \\
\hline $9(1,8)-9(0,9)$ & 25264.01 & 0.06 & $15(4,12)-15(3,13)$ & 114362.56 & -0.06 \\
\hline $2(1,2)-1(0,1)$ & 26638.85 & -0.05 & $17(4,14)-17(3,15)$ & 114364.44 & -0.04 \\
\hline $10(1,9)-10(0,10)$ & 27542.53 & 0.14 & $14(4,11)-14(3,12)$ & 114383.65 & -0.04 \\
\hline $11(1,10)-11(0,11)$ & 30152.26 & 0.14 & $18(4,15)-18(3,16)$ & 114401.67 & -0.02 \\
\hline $8(0,8)-7(1,7)$ & 30442.87 & 0.04 & $13(4,10)-13(3,11)$ & 114411.77 & 0.01 \\
\hline $3(1,3)-2(0,2)$ & 31513.62 & -0.09 & $10(4,6)-10(3,7)$ & 114414.55 & 0.10 \\
\hline $4(1,4)-3(0,3)$ & 36227.87 & -0.15 & $12(4,9)-12(3,10)$ & 114442.45 & -0.01 \\
\hline $19(1,19)-18(0,18)$ & 100496.36 & 0.01 & $9(4,6)-9(3,7)$ & 114522.22 & 0.01 \\
\hline $26(4,22)-26(3,23)$ & 101169.15 & 0.01 & $8(4,5)-8(3,6)$ & 114539.83 & 0.00 \\
\hline $20(0,20)-19(1,19)$ & 101278.05 & -0.04 & $7(4,3)-7(3,4)$ & 114541.85 & 0.02 \\
\hline $22(1,21)-21(2,20)$ & 101333.49 & -0.07 & $22(1,22)-21(0,21)$ & 114552.25 & 0.36 \\
\hline $12(2,11)-11(1,10)$ & 102758.06 & 0.02 & $6(4,2)-6(3,3)$ & 114556.12 & 0.03 \\
\hline $27(2,25)-26(3,24)$ & 103791.43 & 0.04 & $6(4,3)-6(3,4)$ & 114560.32 & -0.01 \\
\hline $24(4,20)-24(3,21)$ & 104876.70 & -0.01 & $5(4,1)-5(3,2)$ & 114563.05 & 0.01 \\
\hline $25(2,24)-25(1,25)$ & 105081.94 & -0.10 & $5(4,2)-5(3,3)$ & 114564.45 & -0.01 \\
\hline $20(1,20)-19(0,19)$ & 105120.35 & 0.09 & $29(1,28)-29(0,29)$ & 116980.68 & 0.10 \\
\hline $13(2,12)-12(1,11)$ & 106230.55 & 0.07 & $23(0,23)-22(1,22)$ & 117268.50 & -0.03 \\
\hline $27(1,26)-27(0,27)$ & 106273.67 & -0.02 & $29(2,28)-29(1,29)$ & 122174.89 & -0.02 \\
\hline $23(4,19)-23(3,20)$ & 106496.20 & 0.05 & $24(0,24)-23(1,23)$ & 122502.40 & -0.00 \\
\hline $21(0,21)-20(1,20)$ & 106664.48 & -0.03 & & & \\
\hline
\end{tabular}

$\mathbf{a}_{\text {obs. }}-\nu_{\text {calc. }}$ 


\section{TABLE 2}

Transitions assigned for the excited vibrational state of $\mathrm{C}_{5} \mathrm{H}_{4}$ and ground state of $\mathrm{C}_{5} \mathrm{H}_{2} \mathrm{D}_{2}$

\begin{tabular}{|c|c|c|c|c|}
\hline \multirow[t]{2}{*}{$J^{\prime}\left(K_{-}^{\prime} K_{+}^{\prime}\right)-J^{\prime \prime}\left(K_{-}^{\prime \prime} K_{+}^{\prime \prime}\right)$} & \multicolumn{2}{|c|}{$\mathrm{C}_{5} \mathrm{H}_{4}$ (vib. state) } & \multicolumn{2}{|c|}{$\mathrm{CH}_{2}(\mathrm{CCD})_{2}$} \\
\hline & $v(\mathbf{M H z})$ & $\Delta \nu(\mathrm{MHz})^{\mathrm{a}}$ & $\nu(\mathrm{MHz})$ & $\Delta \nu(\mathrm{MHz})^{\mathrm{a}}$ \\
\hline $6(0,6)-5(1,5)$ & 18018.53 & 0.03 & & \\
\hline $4(1,3)-4(0,4)$ & 18396.02 & 0.02 & & \\
\hline $5(1,4)-5(0,5)$ & 19343.51 & -0.02 & & \\
\hline $6(1,5)-6(0,6)$ & 20523.09 & -0.01 & 18428.85 & 0.02 \\
\hline $1(1,1)-0(0,0)$ & 21823.07 & 0.04 & 19674.14 & -0.01 \\
\hline $7(1,6)-7(0,7)$ & 21956.17 & 0.04 & 19686.03 & 0.02 \\
\hline $8(1,7)-8(0,8)$ & 23665.60 & -0.05 & 21184.71 & -0.02 \\
\hline $7(0,7)-6(1,6)$ & 24192.14 & -0.00 & & \\
\hline $9(1,8)-9(0,9)$ & 25674.78 & 0.01 & 22945.11 & -0.05 \\
\hline $2(1,2)-1(0,1)$ & 26872.62 & -0.07 & 24214.72 & 0.01 \\
\hline $10(1,9)-10(0,10)$ & 28005.01 & 0.02 & 24986.27 & \\
\hline $8(0,8)-7(1,7)$ & 30419.34 & -0.02 & 27194.30 & 0.00 \\
\hline $11(1,10)-11(0,11)$ & 30674.16 & -0.01 & 27323.91 & 0.00 \\
\hline $3(1,3)-2(0,2)$ & 31751.77 & 0.07 & 28604.97 & -0.01 \\
\hline $9(0,9)-8(1,8)$ & & & 32804.24 & 0.00 \\
\hline $4(1,4)-3(0,3)$ & 36466.88 & -0.03 & 32850.84 & 0.01 \\
\hline $13(1,12)-13(0,13)$ & & & 32928.62 & -0.01 \\
\hline $14(1,13)-14(0,14)$ & & & 36199.12 & 0.00 \\
\hline $22(0,22)-21(1,21)$ & 112209.61 & 0.00 & & \\
\hline $22(1,22)-21(0,21)$ & 114756.95 & 0.00 & & \\
\hline
\end{tabular}

${ }^{a}{ }_{\text {obs. }}-\nu_{\text {calc. }}$

\section{TABLE 3}

Rotational and centrifugal distortion constants for 1,4-pentadiyne

\begin{tabular}{lccc}
\hline Parameter & $\mathrm{C}_{5} \mathrm{H}_{4}(v=0)$ & $\mathrm{C}_{s} \mathrm{H}_{4}(v=1)$ & $\mathrm{C}_{5} \mathrm{H}_{3} \mathrm{D}_{2}(v=0)$ \\
\hline$A(\mathrm{MHz})$ & $19076.77 \pm 0.02^{\mathrm{a}}$ & $19300.82 \pm 1.12$ & $17408.28 \pm 11.2$ \\
$B(\mathrm{MHz})$ & $2859.224 \pm 0.003$ & $2870.209 \pm 0.002$ & $2574.372 \pm 0.013$ \\
$C(\mathrm{MHz})$ & $2520.801 \pm 0.003$ & $2524.656 \pm 0.005$ & $2270.134 \pm 0.013$ \\
$\tau_{1}(\mathrm{kHz})$ & $239.2 \pm 0.1$ & $237.9 \pm 9.0$ & $201.2 \pm 6.3$ \\
$\tau_{2}(\mathrm{kHz})$ & $21.82 \pm 0.01$ & $24.91 \pm 3.8$ & $20.7 \pm 8.9$ \\
$\tau_{3}(\mathrm{kHz})^{\mathrm{b}}$ & $606.8 \pm 1.1$ & $1579 \pm 900$ & $1252 \pm 2195$ \\
$\tau_{\text {aaaa }}(\mathrm{kHz})$ & $-2963 \pm 3$ & $-10231 \pm 4466$ & $-17460 \pm 45000$ \\
$\bar{\tau}_{\text {bbbb }}(\mathrm{kHz})$ & $-11.38 \pm 0.01$ & $-12.96 \pm 1.46$ & $-10.59 \pm 1.71$ \\
$\tau_{\text {cccc }}(\mathrm{kHz})$ & $-3.165 \pm 0.011$ & $-3.94 \pm 0.83$ & $-3.16 \pm 0.57$ \\
\hline
\end{tabular}

arTe uncertainties represent one standard deviation as estimated by the least squares fit. ${ }^{b} \tau_{3}$ is not strictly speaking an independently determinable parameter but it is fixed by setting $R_{6}=0$. See ref. 10 . 
attributed to these species. The expected transition regions often had several weak candidates and several plausible fits could be obtained. It was finally decided not to include this data in the structural analysis.

Satellite transitions from one excited vibrational state were also readily apparent. The transitions that were assigned are listed in Table 2 and derived constants are found in Table 3. Rough relative intensities suggested that this was a symmetric vibrational state, with a frequency of $140 \pm 20 \mathrm{~cm}^{-1}$. By comparison, malononitrile also has an $A_{1}$ vibration at $167 \mathrm{~cm}^{-1}$ assigned to a CCN bending mode. The next three fundamentals in malononitrile are near $367 \mathrm{~cm}^{-1}$ [11].

\section{Dipole moment}

The Stark splittings for 3 transitions were measured at various electric field values. The observed ratios of $\Delta \nu / \epsilon^{2}$ are listed in Table 4 . The resulting dipole moment is $0.516(5) \mathrm{D}$. OCS was used to calibrate the waveguide cell spacing where $\mu_{\mathrm{OCS}}=0.7159(3)[12]$.

\section{STRUCTURE DETERMINATION}

The alternation of intensity and near identity of $I_{\mathrm{a}}+I_{\mathrm{b}}-I_{\mathrm{c}}$ for the two isotopic species is consistent with the expected $C_{2 \mathrm{v}}$ symmetry. For this point group, there are 8 independent structural parameters if the $\mathrm{C}-\mathrm{C} \equiv \mathrm{C}-\mathrm{H}$ linkages are not assumed to have fixed bond angles of $180^{\circ}$. The two isotopic species result in 5 independent moments of inertia and so a completely unambiguous structural determination is not possible. Nevertheless, because the central $\mathrm{HCH}$ angle and the $\mathrm{C}-\mathrm{H}$ interatomic distances can be expected to fall close to "standard" values, some insight into the other structural parameters can be obtained.

One complication is apparent with the moments of inertia that was also observed in malononitrile as well as other molecules that contain two hydrogen atoms projecting above and below a planar, heavy atom framework [13]. In such cases $I_{\mathrm{a}}+I_{\mathrm{b}}-I_{\mathrm{c}}=4 m_{\mathrm{H}} d^{2} \sin ^{2} \theta$, where $d$ is the $\mathrm{C}-\mathrm{H}$ distance and $\theta$ is $1 / 2$

\section{TABLE 4}

Stark coefficients and dipole moment for $\mathrm{C}_{5} \mathrm{H}_{4}$

\begin{tabular}{|c|c|c|c|}
\hline \multicolumn{2}{|c|}{ Transition } & \multirow{2}{*}{$\begin{array}{l}\Delta \nu / \epsilon^{2}(\text { meas. }) \\
\left(\mathrm{MHz} \mathrm{cm}^{2} \mathrm{~V}^{-2}\right) \\
2.69 \times 10^{-6} \\
2.48 \times 10^{-6} \\
1.73 \times 10^{-6}\end{array}$} & \multirow{2}{*}{$\begin{array}{l}\begin{array}{l}\Delta \nu / \epsilon^{2} \text { (obs.) } \\
\left(\mathrm{MHz} \mathrm{cm}^{2} \mathrm{~V}^{-2}\right)\end{array} \\
2.71 \times 10^{-6} \\
2.46 \times 10^{-6} \\
1.72 \times 10^{-6}\end{array}$} \\
\hline $\begin{array}{l}M=0 \\
M=5 \\
M=8\end{array}$ & $\begin{array}{l}1_{11}-0_{00} \\
5_{14}-5_{0 s} \\
8_{17}-8_{08}\end{array}$ & & \\
\hline
\end{tabular}


$(\angle \mathrm{HCH})$. If $d$ is set at $1.105 \AA(1 \AA=0.1 \mathrm{~nm})$ in $\mathrm{C}_{5} \mathrm{H}_{4}$, then the resultant $\angle \mathrm{HCH}$ is $97.1^{\circ}$. This value is much too low to be realistic. The discrepancy results from vibration-rotation interactions involving the heavy in-plane atoms contributing to an inertial defect analogous to the quantity $I_{\mathrm{c}}^{\circ}-I_{\mathrm{b}}^{\circ}-I_{\mathrm{a}}^{\circ}$ $=\Delta$ found in planar molecules. In order to obtain more plausible values in the range of 1.09-1.105 $\AA$ for $d(\mathrm{CH})$ and $106-109^{\circ}$ for $\angle \mathrm{HCH}$, the size of the inertial defect must be $0.3-0.45 \mathrm{u} \AA^{2}$. A defect of $0.33 \mathrm{u} \AA^{2}$ was previously determined for malononitrile from measurements on the normal, $d_{1}$ and $d_{2}$ isotopic species [4]. The necessary moments for a similar determination in $\mathrm{C}_{5} \mathrm{H}_{4}$ are not available and a value of $0.35 \mathrm{u} \AA^{2}$ was assumed for many of the structure calculations.

It was also possible to show that there is an anomalous structural parameter associated with the acetylene groups by a similar calculation. The central $\mathrm{C}-\mathrm{C}-\mathrm{C}$ angle $\left(\angle \mathrm{C}_{2} \mathrm{C}_{3} \mathrm{C}_{4}=2 \theta\right.$, see $\mathrm{Fig}$. 2 for atom numbering) can be calculated from $I_{\mathrm{b}}+I_{\mathrm{c}}-I_{\mathrm{a}}$ if values are assumed for the $\mathrm{C}-\mathrm{C}, \mathrm{C} \equiv \mathrm{C}$, and $\mathrm{C}-\mathrm{H}$ bond distances along with linearity for the $\mathrm{C}-\mathrm{C} \equiv \mathrm{C}-\mathrm{H}$ chains. In that case, $I_{\mathrm{b}}+I_{\mathrm{c}}-I_{\mathrm{a}}=4 \sin ^{2} \theta\left[m_{\mathrm{C}} d_{\mathrm{C}-\mathrm{C}}^{2}+m_{\mathrm{C}}\left(d_{\mathrm{C}-\mathrm{C}}+d_{\mathrm{C}=\mathrm{C}}\right)^{2}+m_{\mathrm{H}}\left(d_{\mathrm{C}-\mathrm{C}}+d_{\mathrm{C}=\mathrm{C}}+d_{\mathrm{CH}}\right)^{2}\right]$. If the bond distances are set at the values found in propyne $\left(d_{C-c}=1.4589 \AA\right.$, $d_{\mathrm{C}=\mathrm{C}}=1.2062 \AA$ and $d_{\mathrm{C}-\mathrm{H}}=1.0562 \AA$ ) [14] then $\angle \mathrm{C}_{2} \mathrm{C}_{3} \mathrm{C}_{4}$ is calculated to be $113.96^{\circ}$. This large value is not likely to result from an inertial defect contribution or some large amplitude vibrational motion for two reasons. First, $I_{\mathrm{b}}+I_{\mathrm{c}}-I_{\mathrm{a}}$ is a large quantity $\left(389.89 \mathrm{u} \AA^{2}\right)$ and a small inertial defect like contribution of $0.4 \mathrm{u} \AA^{2}$ makes only a minor change to any calculated angle. Secondly, the value for $\angle C_{2} C_{3} C_{4}$ is virtually identical when calculated using the moments of $\mathrm{H}_{2} \mathrm{C}(\mathrm{C} \equiv \mathrm{CD})_{2}$. Hence, it appears safe to conclude that either $\angle C_{2} C_{3} C_{4}$ is $3-4.5^{\circ}$ greater than tetrahedral or that the bond lengths and/or linearity assumptions in this calculation are incorrect.

The results of more comprehensive structure computations are listed in Table 5. The calculations were carried out using the STRFIT program discussed by Schwendeman [15]. In this procedure the five independent planar moments of inertia (i.e., $1 / 2\left(I_{\mathrm{b}}+I_{\mathrm{c}}-I_{\mathrm{a}}\right)=\Sigma m_{\mathrm{i}} a_{\mathrm{i}}^{2}=P_{\mathrm{aa}}$, etc.), the planarity condition $\left(\Sigma m_{\mathrm{i}} b_{\mathrm{i}}=0\right)$ and three assumed structural parameters were employed to determine the remaining bond distances and angles. SI and SII show the differences that occur if $P_{\mathrm{cc}}$ is corrected by an inertial defect of $0.35 \mathrm{u} \AA^{2}$. Apart from the large change in the $\mathrm{HCH}$ angle, most other parameters are only slightly affected although $\angle C_{2} C_{3} C_{4}$ is also noted to move closer to the tetrahedral value. SIII and SIV show the result of releasing the linearity restraint on the $\mathrm{CCH}$ chains. For SIII it is seen that a value for $\angle \mathrm{C}_{2} \mathrm{C}_{3} \mathrm{C}_{4}$ much closer to tetrahedral can be obtained but that the acetylene groups must then bend several degrees off the linear axes as if repelling each other. Conversely, SIV shows another fit to the data with a relatively shorter $\mathrm{C}_{2}-\mathrm{C}_{3}$ distance, a very large value for $\angle \mathrm{C}_{2} \mathrm{C}_{3} \mathrm{C}_{4}$ and non-linear acetylene groups now bent to wards each other as judged by $\angle C_{2} C_{3} C_{4}$ being greater than $\angle \mathrm{C}_{1} \mathrm{C}_{3} \mathrm{C}_{5}$. 
TABLE 5

Selected structures which fit the moments of inertia

\begin{tabular}{lccccc}
\hline Method $^{\mathrm{a}}$ & SI & SII & \multicolumn{1}{l}{ SIII } & \multicolumn{1}{l}{ SIV } & Pref. \\
\hline$\Delta^{\mathrm{b}}\left(\mathrm{u} \mathrm{A}^{2}\right)$ & 0.0 & 0.35 & 0.35 & 0.35 & \\
$\mathrm{C}_{1} \mathrm{H}_{1}(\mathrm{~A})$ & $1.055 \mathrm{a}$ & $1.055 \mathrm{a}$ & $1.055 \mathrm{a}$ & $1.055 \mathrm{a}$ & $1.055(10)$ \\
$\mathrm{C}_{3} \mathrm{H}_{3}$ & $1.090 \mathrm{a}$ & $1.090 \mathrm{a}$ & $1.089 \mathrm{a}$ & $1.09 \mathrm{a}$ & $1.090(10)$ \\
$\mathrm{C}_{1} \mathrm{C}_{2}$ & 1.203 & 1.205 & $1.207 \mathrm{a}$ & 1.206 & $1.206(10)$ \\
$\mathrm{C}_{2} \mathrm{C}_{3}$ & 1.463 & 1.468 & 1.475 & $1.459 \mathrm{a}$ & $1.471(10)$ \\
$\mathrm{H}_{3} \mathrm{C}_{3} \mathrm{H}_{3} \cdot$ (deg.) & 98.3 & 107.0 & 107.0 & 107.0 & $107.0(20)$ \\
$\mathrm{H}_{1} \mathrm{C}_{3} \mathrm{C}_{2}$ & $180.0 \mathrm{a}$ & $180.0 \mathrm{a}$ & 177.5 & 176.7 & $178.8(20)$ \\
$\mathrm{C}_{1} \mathrm{C}_{2} \mathrm{C}_{3}$ & 179.9 & 179.4 & 176.3 & 176.3 & $177.8(20)$ \\
$\mathrm{C}_{2} \mathrm{C}_{3} \mathrm{C}_{3}$ & 113.8 & 112.9 & 110.2 & 116.6 & $111.5(20)$ \\
$\mathrm{C}_{1} \mathrm{C}_{3} \mathrm{C}_{5}$ & 113.9 & 113.4 & 113.5 & 113.3 & $113.4(10)$ \\
$\mathrm{H}_{1} \mathrm{C}_{3} \mathrm{H}_{5}$ & 113.9 & 113.6 & 113.2 & 114.1 & $113.4(10)$ \\
\hline
\end{tabular}

aSI-SIV calculated by fixing 3 parameters and fitting the others using the STRFIT program [15]. The letter " $a$ " after a parameter indicates it was held fixed during the fitting. The unit $\AA=0.1 \mathrm{~nm}$. ${ }^{b} I_{\mathrm{a}}+I_{\mathrm{b}}-I_{\mathrm{c}}+\Delta=2 P_{\mathrm{aa}}$. The listed value of $\Delta$ was used during the fitting process. ${ }^{c}$ Preferred structure; see text.

\section{DISCUSSION}

Bond distances for the 4 bond types found in $\mathrm{C}_{5} \mathrm{H}_{4}$ generally do not deviate widely in the absence of perturbations from conjugation, electronegative groups or steric interactions. Typical values for these bond distances are listed in Table 6 for several species. It is reasonable to expect that values similar to these examples should also occur in $\mathrm{C}_{5} \mathrm{H}_{4}$. The sets of 4 bond distances for the various calculations in Table 5 compare favorably with this expectation.

It is more difficult to choose an unambiguous set of bond angles for $\mathrm{C}_{5} \mathbf{H}_{4}$. Rejection of SI and SIV as plausible structures can be made due to their unusual values for $\angle \mathrm{HCH}$ and $\angle \mathrm{C}_{2} \mathrm{C}_{3} \mathrm{C}_{4}$, respectively. However, choosing

TABLE 6

Selected values of comparable bond distances

\begin{tabular}{lllllr}
\hline Species & $\mathrm{CH}_{\text {acet }}$ & $\mathrm{CH}_{\text {meth }}$ & $\mathrm{C} \equiv \mathrm{C}$ & $\mathrm{C}-\mathrm{C}$ & Ref. \\
\hline $\mathrm{C}_{2} \mathrm{H}_{2}$ & 1.058 & & 1.207 & & 16 \\
$\mathrm{CH}_{2}(\mathrm{C}=\mathrm{N})_{2}$ & & 1.088 & & 1.468 & 4 \\
$\mathrm{CH}_{3} \mathrm{CCH}$ & 1.056 & 1.105 & 1.206 & 1.459 & 14 \\
$\mathrm{HCCCHO}$ & 1.054 & & 1.205 & 1.449 & 2 \\
$\mathrm{SiH}_{3} \mathrm{CCH}$ & 1.058 & & 1.208 & & 17 \\
$\left(\mathrm{CH}_{3}\right)_{3} \mathrm{CCCH}$ & 1.056 & & 1.209 & 1.496 & 18 \\
$\mathrm{C}_{6} \mathrm{H}_{5} \mathrm{CCH}$ & 1.055 & & 1.208 & 1.448 & 19 \\
$\mathrm{C}_{5} \mathrm{H}_{4}$ & $1.055(10)$ & $1.090(10)$ & $1.206(10)$ & $1.471(10)$ & \\
\hline
\end{tabular}


between SII and SIII is not as clear cut. Deviations from tetrahedral values about a central carbon of $2-3^{\circ}$ and deviations from linearity for $\pi$ systems such as cyanides and acetylenes are not without precedent. Nevertheless, it is clear that both of these structures point to an interaction involving the acetylene linkages which increases the distance between them. The data strongly argues that either $\angle C_{2} C_{3} C_{4}$ is close to the tetrahedral value with the acetylene groups deviating by about 3-4 $4^{\circ}$ from linearity or linearity is retained but $\angle \mathrm{C}_{2} \mathrm{C}_{3} \mathrm{H}_{4}$ opens to about $113^{\circ}$. Of course a range of structures between these two possibilities is also consistent with the data. Since there is more precedence for deviations of acetylene groups from linearity than for four coordinate carbon with a bond angle as large as $113^{\circ}$, it seems more likely to us that the actual situation corresponds more closely to structure SIII than SII. However, this is speculation; further work will be needed to more precisely delineate the angular parameters associated with the acetylene groups. In the interim, it is safe to conclude that the structure of $\mathrm{C}_{5} \mathrm{H}_{4}$ has parameters within about $0.01 \AA$ and $2^{\circ}$ of the average of SII and SIII. This structure is listed in the last column of Table 5 as the best estimate available with the present data.

Although the precise nature of the anomaly in the acetylenic bond angles cannot be uniquely resolved with the MW data, the effect is undoubtedly associated with the four $\pi$ orbitals which are nominally degenerate. Brogli et al. [1] have outlined the type of through space and through bond interactions including a breakdown of the $\sigma / \pi$ separation which leads to loss of the degeneracy. It was estimated that the four $\pi$ molecular orbitals are slightly destabilized from the zeroth order position and spread over $0.75 \mathrm{eV}$. Presumably this also leads to the angular perturbation delineated by the microwave analysis.

\section{ACKNOWLEDGEMENT}

R.L.K. is grateful to the U.M. and N.B.S. for enabling him to participate as a guest worker at the N.B.S. laboratory where this study was completed. The work done at the University of Michigan was supported by grants to R.L.K. and A.J.A. from the National Science Foundation.

\section{REFERENCES}

1 F. Brogli, E. Heilbronner, J. Wirz, E. Kloster-Jensen, R. G. Bergman, K. P. C. Vollhardt and A. J. Ashe III, Helv. Chim. Acta, 58 (1975) 2620.

2 M. Sugie, T. Kukuyama and K. Kuchitsu, J. Mol. Struct., 14 (1972) 333.

3 A. E. Jungk, Chem. Ber., 105 (1972) 1595.

4 E. Hirota and Y. Morino, Bull. Chem. Soc. Jpn., 33 (1960) 158, 705.

5 G. Winnewisser and C. M. Walmsley, Astrophys. Space Sci., 65 (1979) 83.

6 A. E. Douglas, Nature (London), 269 (1977) 130.

7 G. Casnati, A. Quilico, A. Ricca and P. Vitafinzi, Gazz. Chim. Ital., 96 (1966) 1064;

D. A. Ben-Efraim and F. Sondheimer, Tetrahedron, 25 (1969) 2823. 
8 R. D. Suenram and F. J. Lovas, J. Am. Chem. Soc., 102 (1980) 7180.

9 J. K. G. Watson, J. Chem. Phys., 46 (1967) 1935.

10 W. H. Kirchhoff, J. Mol. Spectrosc., 41 (1972) 333.

11 E. Hirota, J. Mol. Spectrosc., 7 (1961) 242.

12 J. M. L. J. Reinartz and A. Dymanus, Chem. Phys. Lett., 24 (1974) 346.

13 V. W. Laurie, J. Chem. Phys., 28 (1958) 704.

14 C. C. Costain, J. Chem. Phys., 29 (1958) 864.

15 R. H. Schwendeman, in D. R. Lide and M. A. Paul (Eds.), Critical Evaluation of Chemical and Physical Structural Information, National Academy of Sciences, Washington, 1974, p. 74.

16 M. D. Harmony, V. W. Laurie, R. L. Kuczkowski, R. H. Schwendeman, D. A. Ramsay, F. J. Lovas, W. J. Lafferty and A. G. Maki, J. Phys. Chem. Ref. Data, 8 (1979) 619.

17 M. C. L. Gerry and T. M. Sugden, Trans. Faraday Soc., 61 (1965) 2091.

18 L. J. Nugent, D. E. Mann and D. R. Lide Jr., J. Chem. Phys., 36 (1962) 965.

19 A. P. Cox, I. C. Ewart and M. W. Stigliani, J. Chem. Soc. Faraday Trans. 2, 71 (1975) 504. 